\title{
Mechanical and Microstructural analysis of Dissimilar material joining by Laser welding
}

\author{
RADHA KRISHNAN B ${ }^{1}$ and Vijayan $\mathrm{V}^{2}$ \\ ${ }^{1}$ Nadar Saraswathi College of Engineering and Technology \\ ${ }^{2} \mathrm{~K}$ Ramakrishnan College of Technology
}

June 25, 2020

\begin{abstract}
This paper proposed the comparative study on Incoloy $825 \mathrm{Ni}$-based alloy and AISI 316L austenitic stainless steel dissimilar joints. Welding is accomplished by Nd: YAG pulsed laser beam welding process. This paper is about to investigate the process parameters like laser focal diameter, Power, and pulse frequency in LBW welding of above dissimilar plates. Characterization was conducted by optical microscopy, electron microscopy to understand the microstructural changes during welding. Microhardness and tensile tests are carried out to study the evolution of mechanical properties of solder joints. Based on the research work, laser beam welding has certain advantages over other welding techniques due to its less heat affected zone, high power intensity, high repetition rate. Among various analytical and experimental optimization methods, the Taguchi method is more efficient. So this experimentation is about to prove the weld efficiency of dissimilar metal can meet the requirements in oil and gas industries and other industries.
\end{abstract}

\begin{abstract}
This paper proposed the comparative study on Incoloy 825 Ni-based alloy and AISI 316L austenitic stainless steel dissimilar joints. Welding is accomplished by Nd: YAG pulsed laser beam welding process. This paper is about to investigate the process parameters like laser focal diameter, Power, and pulse frequency in LBW welding of above dissimilar plates. Characterization was conducted by optical microscopy, electron microscopy to understand the microstructural changes during welding. Micro-hardness and tensile tests are carried out to study the evolution of mechanical properties of solder joints. Based on the research work, laser beam welding has certain advantages over other welding techniques due to its less heat affected zone, high power intensity, high repetition rate. Among various analytical and experimental optimization methods, the Taguchi method is more efficient for predicting the results. So this experimentation is about to prove the weld efficiency of dissimilar metal can meet the requirements in oil and gas industries and other industries.
\end{abstract}

Keywords: Laser Beam Welding; AISI 3161; Incoloy 825; weld joints; Nd: YAG

\section{Introduction}

This nickel alloy825, along with 316L SS, is used in the oil and gas industry where the usage of sulphuric and nitric acids is high. These materials are used in heat exchangers, boilers, food industry, and in areas such as pollution control board, oil and gas retrieval workplace, chemical processing station, acid production industries. They are best suited for the marine environment because it has a high resistance against corrosion by seawater.LNG pipelines are required to maintain sufficient rigidity, ductility, and corrosive resistance at low temperatures. So this nickel alloy825and 316L SS combination is best suited to satisfies the requirements. Results of crevice corrosion tests and pitting corrosion tests indicate that UNS N08825(alloy 825) has high chloride-induced localized corrosion resistance. Because of its high concentration of chromium and molybdenum, its critical pitting temperature and crevice corrosion temperature in contaminated chloride seawater 
are significantly higher than in alloy N08028 (alloy 28) and UNS N06625 (alloy 625) [1]. Investigated the effect of Nd: YAG pulsed laser-welded super-duplex stainless steel (SDSS) by varying parametric parameters such as welding speed, laser power, focal location, and pulse frequency. Two different models measure tensile strength, and the tensile fracture is defined by ductile fracture and smaller grains [2]. The Co2 laser welding investigated, in which heating effects are improved with a pulse time increase for a given average power, travel speed, and APPD and improved by higher APPD, thus allowing controlled laser welding of materials. [3]. The Nd: YAG laser diode-pumped (maximum output of $4.4 \mathrm{~kW}$ ) is usually used in the case of copper and aluminum. It is used to detect the influence of process parameters based on the capacity of the laser welders and determines that the addition of silicone in aluminum optimizes copper and aluminum soldering [4]. This article describes how solidification produces a $100 \%$ austenite microstructure, as demonstrated by EBSD scans using a conventional Gaussian beam. However, chromium, molybdenum, and sulfur microsegregation are visible in the structure at the outer edges of cells. When a diffractive optical element uses a uniform irradiance distribution, the fusion zone produces a partially austenitic structure. The grain size remains $(200 \mu \mathrm{m})$, but $\pi$-ferrite is also limited. It may be due to higher quench intensity using square uniform irradiance distribution [5]. Such studies show that, due to the different soldering strength and soldering duration, the impact of process parameters has a significant effect on the cooling speed. The heat-affected zone and fusion zone were observed as the solder power was increased, and solder velocity was respectively lowered. A significant result can be drawn in this study that the average increase in temperature is lower than the higher heat consumption limit [10]. For the bellows connection and the flanged joint of an expansion joint with STS316L and INCOLOY 825 materials, proper welding conditions were found in this study. Of INCOLOY 825, the hardness of the base metal was from 200 to $210 \mathrm{Hv}$, but the hardness of the solder increased to 220 to $330 \mathrm{Hv}$ because the structure became more microscopic after soldering. However, the value of the single-pass welding was low because of the two-pass soldering the soldering was soft [11]. The geometrical characteristics of the bead play a significant part in determining the consistency of every weld joint, taking into account its importance, i.e., bead center, bead volume, and the principal effects of output responses on change in control factors. The bead characteristics play a crucial role. RSM is used for the experimental data collected, and models are projected for adequacy testing for each output response. The diagrams are often analyzed by measuring the patterns between input and reference parameters. The RSM models can also be used to optimize the process. TIG and MIG welding are recognized as the choices for welding small components. But it requires skill and has some disadvantages. High-energy laser beam welding is shown to support Ni-based alloys for welding. Welding is conducted by a series of short pulses that melts the metal to create high-quality weld. Therefore, efforts are undertaken to join nickel alloy 825 and 316L SS using laser beam welding Nd: YAG and to analyze microstructural changes in the welded area.

\section{Materials Selection}

\section{a) Stainless steel $316 \mathrm{~L}$}

Grade 316 is the second of the austenitic stainless steels to bear the standard molybdenum, with the importance of 304. Total corrosion resistance properties for molybdenum are 316 higher than grade 304; in chloride environments, this is especially highly resistant to pitting and crevices. Grade 316L, 316 low carbon version, and immune to sensitivity (precipitated carbide grain boundary). It is thus commonly used in components with heavy welded gages (around $6 \mathrm{~mm}$ ). Often, between 316 and $316 \mathrm{~L}$ stainless steel, there is no significant price difference. The austenitic composition is also very durable, even at cryogenic temperatures for these classes. 316L stainless steel provides higher creep, rupture stress, and tensile strength at high temperatures compared with chromium-nickel austenitic stainless steel. Table 1 and 2 shows the chemical and mechanical properties of 316L stainless steel.

Table 1. chemical composition rate of stainless steel-316L

\begin{tabular}{llllllllll}
\hline Grade & $\mathrm{N}$ & $\mathrm{Ni}$ & $\mathrm{C}$ & $\mathrm{Mn}$ & $\mathrm{Si}$ & $\mathrm{P}$ & $\mathrm{S}$ & $\mathrm{Cr}$ & $\mathrm{Mo}$ \\
\hline Ranges (\%) & 0.1 & $10.5-14.5$ & $0.025-0.03$ & $1-2$ & $0.70-0.75$ & 0.040 & $0.01-0.03$ & $15-20$ & $2-4$ \\
\hline
\end{tabular}


Table. 2 Mechanical properties of SS 316L

\begin{tabular}{lll}
\hline S.No & Properties & Range \\
\hline 1 & Tensile stress (MPa) & $480-550$ \\
2 & Yield stress(MPa) & $150-200$ \\
3 & Elongation (\%) & $35-50$ \\
4 & Hardness (HB) & $210-250$ \\
\hline
\end{tabular}

Grade 316L is more carbide resistant and can be used at high temperatures. Grade 316H has higher strength at high temperatures, some of which are applied at a temperature of over $500^{\circ} \mathrm{C}$ to structural and pressurecontaining applications. 316 is commonly considered to be the standard "sea grade stainless steel," but not resistant to warm marine water. 316 indicates surface erosion, usually visible in brown coloring, in many marine environments. The resultant tears and rough surface finish are mainly linked to the excellent weldability with and without filler metals by all standard fusion and resistance techniques. To optimum corrosive resistance, significant soldered parts in Grade 316 require post-solder annealing. This process was no needed for the use of oxyacetylene soldering methods in stainless steel 316L.316L.

\section{b) $I N C O L O Y 825$}

The corrosion resistance is the extraordinary attribute of Incoloy 825 shown in table 3 . Once depleted and oxidized, Incoloy 825 prevents rust, pitting and cravings, intergranular corrosion, and stress cracking. It is especially useful in sulfuric and phosphoric acids, flue gases, saline gas, oil wells, and marine water containing sulfur.

Table 3. chemical composition rate of Incoloy 825

\begin{tabular}{llllllllll}
\hline Grade & $\mathrm{Fe}$ & $\mathrm{Ni}$ & $\mathrm{C}$ & $\mathrm{Mn}$ & $\mathrm{Si}$ & $\mathrm{Mb}$ & $\mathrm{S}$ & $\mathrm{Cr}$ & $\mathrm{Al}$ \\
\hline Ranges (\%) & $20-22$ & $30-45$ & $0.025-0.03$ & $1-2$ & $0.30-0.5$ & $2-4$ & $0.01-0.03$ & $19-25$ & $0.1-0.3$ \\
\hline
\end{tabular}

Ships, valves, automobiles, semiconductive equipment, flow and pressure sensors, and even aircraft, are used widely in industrial machines. As conventional fossil fuels are recently depleted, more than ever, natural liquefied petroleum is required as alternative energy, thereby increasing demand for bellows on LNG ships. The alloy SS316L and INCOLOY 825 are used as a material for the bellows of LNG vessels that is resistant to corrosion and low - temperature fragility. SS316L is low - carbon, stainless steel with less than 0.03 percent carbon content that avoids intergranular corrosion by welding and retains resistance and Power at low temperatures. This study aims to develop the best welding parameters of unique materials for INCOLOY 825 and SS316L for use at low temperatures and to evaluate the reliability of the product. To this end, we show that best suited to joining the material are optimum welding conditions.

\section{Experimental Methodology}

Laser beam welding

ECO 2600 Pulsed laser beam welding performs the soldering process. In particular, for small businesses and young companies that are making the initial steps in this area, this new development offers an economical introduction to laser welding. Its laser soldering device is, of course, also perfect with experts who want to increase their soldering abilities. It is lightweight and portable and can be ready for use quickly and profoundly reliable to satisfy increasing consumer requirements, including tools and die manufacturing. In the context of user experience, in particular, no sacrifice was made. The $150 \mathrm{~kg}$-carrying motor-controlled table $(\mathrm{x} / \mathrm{y} / \mathrm{z})$ allows for synchronous laser axis welding. This is also true for the motorized rotor axis shown in figure 1 using four axes. 


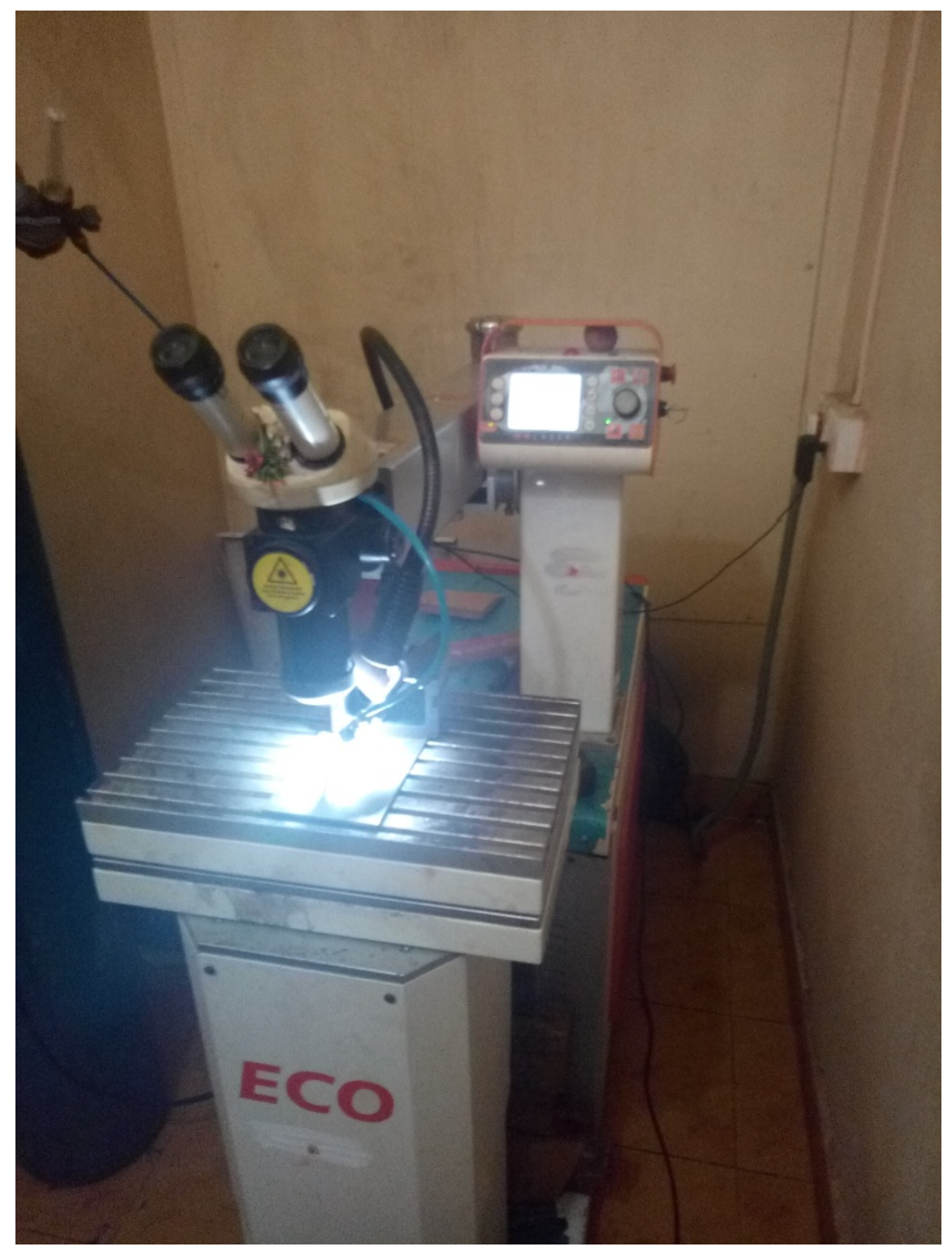

Fig. 1. Laser beam welding

Taguchi analysis 


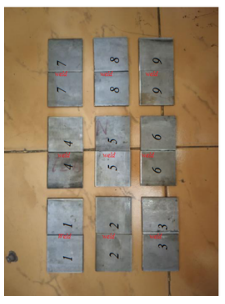

Taguchi has proposed a new method for designing experiments based on clear guidelines. This procedure uses a unique array called orthogonal arrays. These standard arrays specify a small number of experiments so that all factors affecting the performance parameter can be fully identified, as shown in table 4 . The orthogonal array L9 is intended to understand the effects of three separate factors, each with three levels of the factor. This array assumes that the interaction of two factors is not possible. Although no assumption of the interaction model is valid in many cases, there are cases in which clear evidence of interaction exists. 
The interaction between material properties and temperature would be a typical case of interaction, the microstructural view used to analyze the welding affected zone from welded plated shown in fig 2 .

Fig. 2. Dissimilar material weld by laser beam welding

Its hypothesis - a test process for assessing mean differences between two or more treatments. Even when more than one unit is used for replication treatment, it is still simpler in the statistical analysis. The researcher improves the chances that the experimental process is to help find what changes. The ideal welding parameters for the best weld can be found here.

Table 4. Parameters for Taguchi analysis

\begin{tabular}{llll}
\hline Specimen No. & Laser Dia. Mm & Power $\mathrm{W}$ & Frequency Hz \\
\hline 1 & 0.3 & 45 & 8 \\
2 & 0.3 & 44 & 9 \\
3 & 0.3 & 46 & 10 \\
4 & 0.4 & 44 & 9 \\
5 & 0.4 & 45 & 10 \\
6 & 0.4 & 46 & 8 \\
7 & 0.5 & 44 & 10 \\
8 & 0.5 & 45 & 8 \\
9 & 0.5 & 46 & 9 \\
\hline
\end{tabular}

\section{Results and Discussion}

Mechanical behaviors The average durability of the base metal is $230 \mathrm{HV}$ shown in table 5 . In comparison to the interface and the base material, hardness values are higher in the fusion soldering area. The strength of the sold machine in the middle, cap, and root was 195, 198, and $197 \mathrm{HV}$. Compared to all the other areas, the primary material area is found to be softer, and therefore tensile failure can occur in the weaker portion of the base material. The findings of the ANOVA table for the selection of the best three specimens show that the 9th individual specimen has a higher-yielding intensity, an elongation of about 15,5\%, and the addition of a tensile test caused a fracture in the parent métal. This can be achieved with 9 specimens out of 3 specimens that have the highest hardness tests and microstructure. Table 5. Mechanical behaviors of welded specimen

\begin{tabular}{lll}
\hline Specimen No. & Hardness HV & Tensile Strength MPa \\
\hline 1 & 165 & 215 \\
2 & 198 & 365 \\
3 & 205 & 380 \\
4 & 176 & 212 \\
5 & 186 & 234 \\
6 & 345 & 415 \\
7 & 214 & 236 \\
8 & 163 & 212 \\
9 & 425 & 422 \\
\hline
\end{tabular}

Metallurgical analysisThere are no detectable defects on the weld surface of the sold bead or its adjacent areas from the intersection of the welding joint that is apparent in the specific region. The welding characteristics of the pulsed laser beams indicate no welding crises among the two materials due to the specimen welded in energy $2.5 \mathrm{~J}$ and also weld beads, and due to stainless steel 316L, this can occur, and Incoloy 825 has a natural resistance to crashes as well as optimum soldering parameters. The sold metal shows no discontinuities. The 
efficacy of the gas shielding to resist oxidation, high porosity, and gas and gas inclusions is demonstrated. All the laser-welded in the conduction mode were direct heating and transmission of energy. Figures 3 and 4 show the microstructure analyzes of SS316L and Incoloy. The direct heating mechanism involved the absorption by the material surface of the beam energy. The laser intensity activates some of the minute surface shoes, the 9 th weld zone microstructure, heat - affected area in figure 5 .
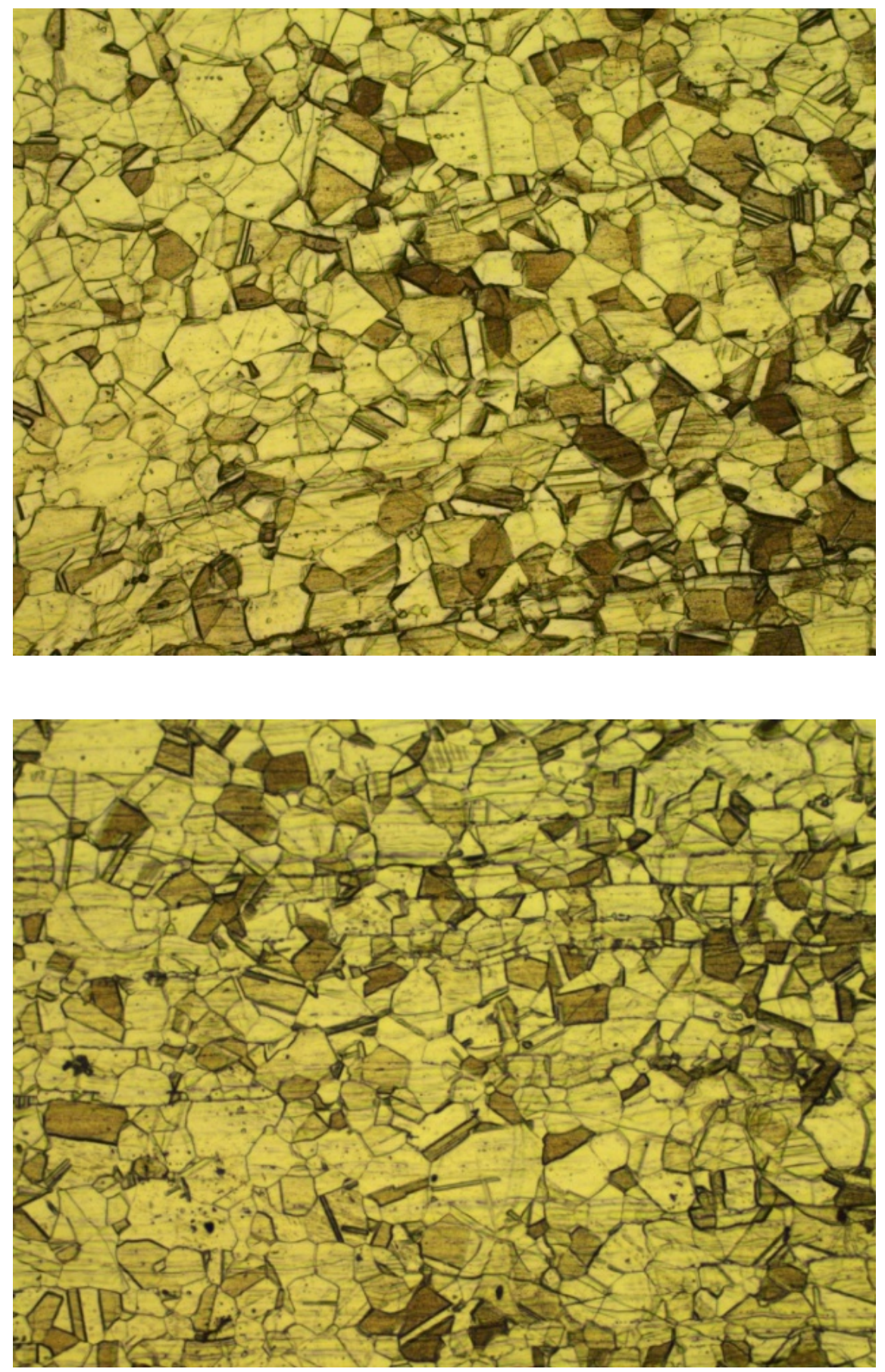

Fig 3. Microstructure analysis of Incoloy Fig 4. Microstructure analysis of SS316L 


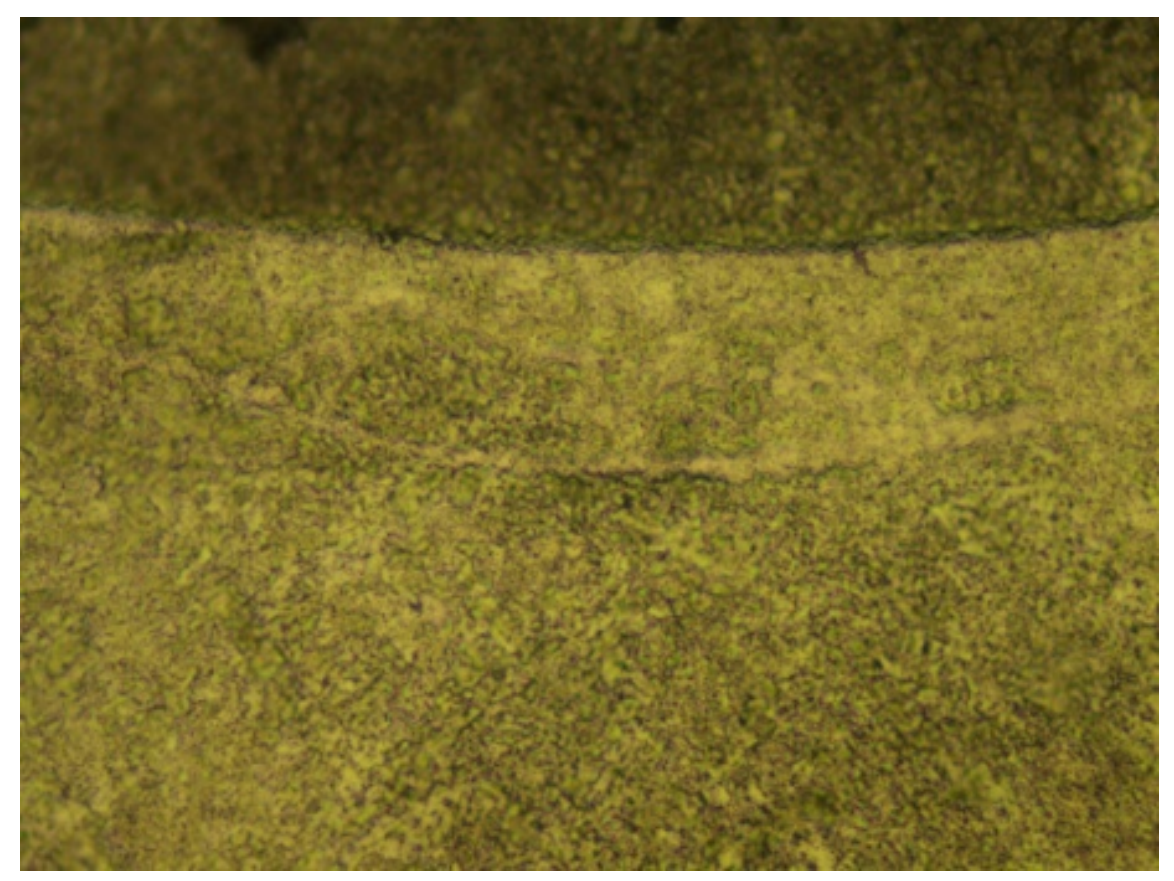

Fig. 5. Welding zone of dissimilar materials

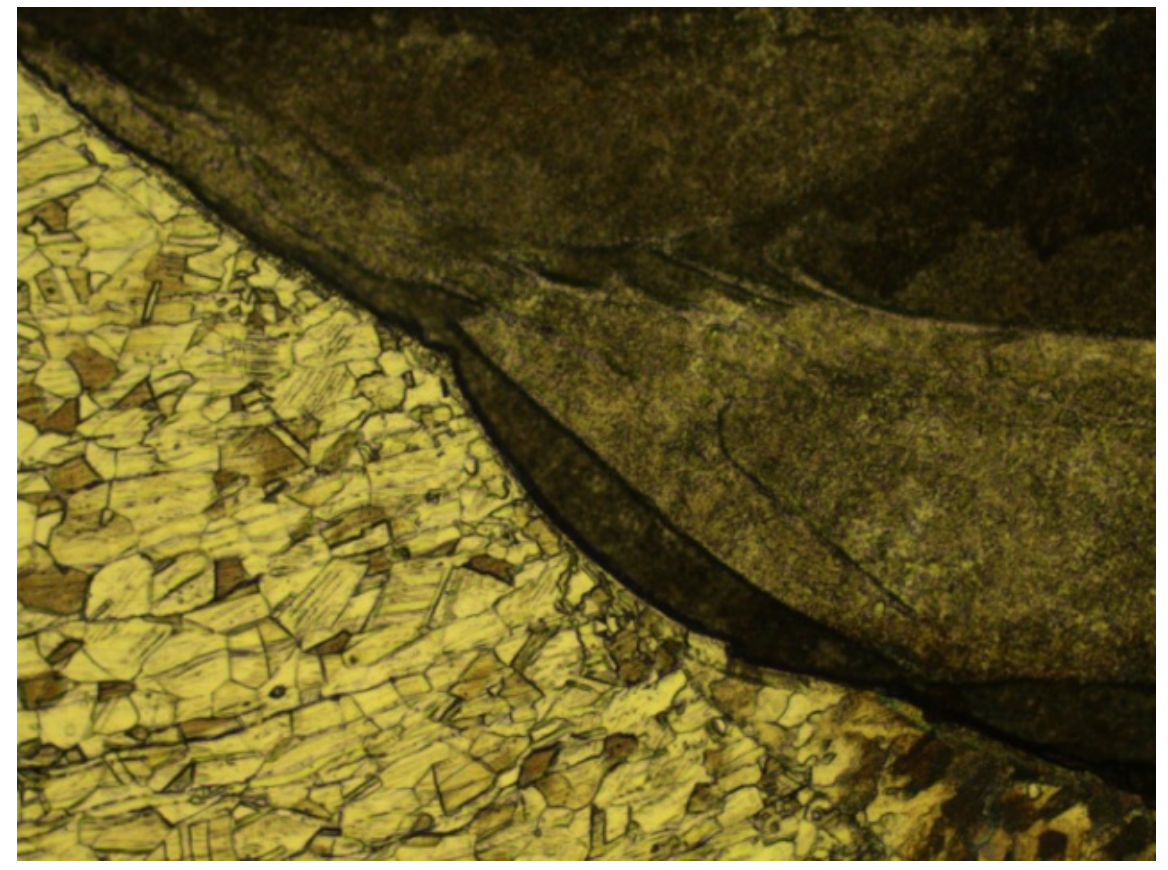




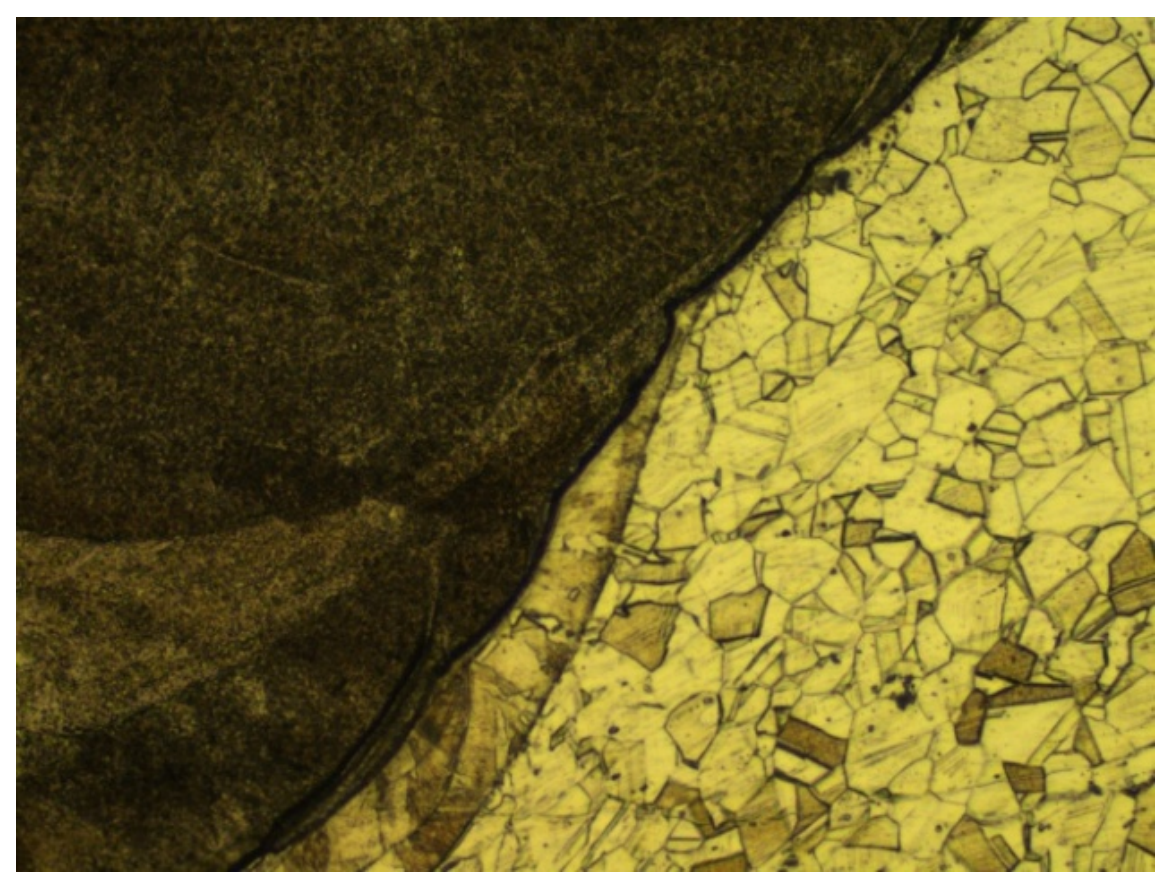

Fig. 6. Fusion zone of dissimilar welding (Left fusion and Right fusion)

In the direct heating and energy transmission mode, they all were laser soldered. The direct heating mechanism involved beam energy absorption by the surface of the material. The high laser strength is the cause of several small surface holes. The 9th welding zone microstructure, the heat zone, the fusion zone are illustrated in Figure 6.

\section{ANOVA Table}

From the experimentation value, the L9 orthogonal array was made using the design expert software 7.0, and the ANOVA Table 6 was shown below.

Table 6. Analysis Of Variance Table

\begin{tabular}{llllll}
\hline ANOVA & ANOVA & ANOVA & ANOVA & ANOVA & ANOVA \\
for & for & for & for & for & for \\
Response & Response & Response & Response & Response & Response \\
Surface & Surface & Surface & Surface & Surface & Surface \\
Linear & Linear & Linear & Linear & Linear & Linear \\
Model & Model & Model & Model & Model & Model \\
\hline Analysis of & Analysis of & Analysis of & Analysis of & Analysis of & Analysis of \\
variance & variance & variance & variance & variance & variance \\
table & table & table & table & table & table \\
[Partial sum & [Partial sum & [Partial sum & [Partial sum & [Partial sum & {$[$ Partial sum } \\
of squares - & of squares - & of squares - & of squares - & of squares - & of squares - \\
Type III $]$ & Type III] & Type III] & Type III] & Type III] & Type III] \\
Source & Sum of & Df & Mean Square & F Value & p-value Prob \\
& Squares & & & & F F
\end{tabular}




\begin{tabular}{|c|c|c|c|c|c|c|}
\hline $\begin{array}{l}\text { ANOVA } \\
\text { for }\end{array}$ & $\begin{array}{l}\text { ANOVA } \\
\text { for }\end{array}$ & $\begin{array}{l}\text { ANOVA } \\
\text { for }\end{array}$ & $\begin{array}{l}\text { ANOVA } \\
\text { for }\end{array}$ & $\begin{array}{l}\text { ANOVA } \\
\text { for }\end{array}$ & $\begin{array}{l}\text { ANOVA } \\
\text { for }\end{array}$ & \\
\hline Response & Response & Response & Response & Response & Response & \\
\hline Surface & Surface & Surface & Surface & Surface & Surface & \\
\hline Linear & Linear & Linear & Linear & Linear & Linear & \\
\hline Model & Model & Model & Model & Model & Model & Significant \\
\hline B-Frequency & 600 & 1 & 600 & 0.150978 & 0.7136 & \\
\hline C-Laser Dia & 54 & 1 & 54 & 0.013588 & 0.9117 & \\
\hline Residual & 19870.5 & 5 & 3974.1 & & & \\
\hline Cor Total & 109098 & 8 & & & & \\
\hline
\end{tabular}

The F-value of model 7.48 means that the model is important. "Prob > F" value below 0.0500 shows significant model terms..

\section{Hosted file}

image8.emf available at https://authorea.com/users/336730/articles/462421-mechanical-andmicrostructural-analysis-of-dissimilar-material-joining-by-laser-welding

Fig. 7. Laser power vs. Frequency on Tensile Strength

From Figure 7 above, strength played an essential role in tensile strength - if laser beam tensile strength increases, tensile strength gradually increases. The output increases from $44 \mathrm{~W}$ to $46 \mathrm{~W}$ in the same example. The tensile Power from $188 \mathrm{MPa}$ to $510 \mathrm{MPa}$ has increased dramatically. The rate of increase varies slightly in tensile strength. The tensile strength is not impaired.

\section{Hosted file}

image9.emf available at https://authorea.com/users/336730/articles/462421-mechanical-andmicrostructural-analysis-of-dissimilar-material-joining-by-laser-welding

Fig. 8. Laser Dia. Vs. Frequency on Tensile Strength

From the above figure 8 , it is evident that there is a slight change in tensile

Strength. Both Laser Diameter and Frequency did not affect the tensile strength of the Incoloy 825 and AISI $316 \mathrm{l}$ weld plate. Only slight changes occur in tensile strength.

\section{Hosted file}

image10.emf available at https://authorea.com/users/336730/articles/462421-mechanical-andmicrostructural-analysis-of-dissimilar-material-joining-by-laser-welding

Fig. 9. Laser power Vs. Laser Diameter on Tensile Strength

From the above figure 9, it is evident that Power plays a significant role in tensile strength if the Laser Diameter of Laser Beam Increases, there is a gradual increase of Tensile Strength. In the same instance, the Power increases from $44 \mathrm{~W}$ to $46 \mathrm{~W}$ there is a drastic increase in Tensile Strength from $188 \mathrm{MPa}$ to 510 $\mathrm{MPa}$. From the above Observations, it is inferred that the Power Plays the Major Role in increasing the tensile values of the welded samples. The Remaining two parameters have a low influence on comparatively.

Tensile strength $=-5079.17+30$ *laser diameter $+121.5^{*}$ Power $+{ }^{*}-10$ Frequency is the mathematical model observed from ANOVA table.

\section{Conclusion}

The material INCOLOY 825 and SS316L are having high resistance to corrosion and possess excellent mechanical properties. They find suitable applications in the oil and gas industry, marine structures. Laser 
beam welding was chosen for its accuracy and precision, and also it has the least heat affected zone compared with other welding processes. We chose the L9 Orthogonal method to find the best parameters of our welding process. In this research, we choose only 3 parameters for the analytical purpose. By these 3 parameters, we made 9 specimens for our investigations, from the experimental study, it is concluded that significant improvements were found.

- From the Taguchi's L9 Orthogonal Method of optimization, the optimized parameters are $0.5 \mathrm{~mm}$ beam diameter, $46 \mathrm{~W}$ power and $9 \mathrm{~Hz}$ frequency which yields the maximum Tensile Strength to the welded samples of SS316L and INCOLOY 825 using Nd: YAG Pulsed Laser Beam Welding Process and its shows below as advantages as well as limitations. From the ANOVA analysis, laser power played a significant role in the welding of materials.

- Higher hardness values were found, which are appropriate in the practical field of application for the functional aspects of the weld.

- Laser welding gives a good quality weld and provides greater strength with good depth of penetration. A high tensile value of $510 \mathrm{Mpa}$ was obtained from the $9^{\text {th }}$ specimen.

Failure occurs at the welded joint because of the pores generated due to the $1 \mathrm{~mm}$ depth of penetration.

\section{References}

[1] Jalal Kangazian., Morteza Shamanian., Mechanical and microstructural evaluation of SAF 2507 and incoloy825 dissimilar welds. Journal of Manufacturing Processes 26 (2017) 407-418.

[2] Jalal Kangazian, Morteza Shamanian, Ali Ashrafi, Dissimilar welding between SAF 2507 stainless steel and Incoloy 825 Ni-based alloy: The role of microstructure on corrosion behavior of the weld metals. Journal of Manufacturing Processes 29 (2017) 376-388.

[3] Pyung-Su Kim, So-Young Choi, Young-Sik Kim and Jong-Do Kim,A Study on the Weldability of INCOLOY 825 Alloys and STS316L Alloys, Advanced Materials Research (2015) Vol. 1110, pp 118-124.

[4] Qiang Guo, Yuan Li, Jiong Qian, Haobo Yu1, Changfeng Chen, Study of the pitting corrosion at welding joints of Inconel 625 alloy under high temperature and high $\mathrm{H} 2 \mathrm{~S} / \mathrm{CO} 2$ partial pressure, Int. J. Electrochem. Sci., 12 (2017) 8929 - 8943 .

[5] JL Caron, JW Sowards, Weldability of Nickel-Base Alloys, In Comprehensive Materials Processing;Bayraktar, E., Ed.; Elsevier Ltd., 2014; Vol. 6, pp 151-179.

[6] Navid Sayyar, Morteza Shamanian, Behzad Niroumand, Arc weldability of Incoloy 825 to AISI 321 stainless steel welds, Journal of Materials Processing Tech. S0924-0136(18)30316-9.

[7] Abdel-Monem El-Batahgy, Laser Beam Welding of Austenitic Stainless Steels - Similar Butt and Dissimilar Lap Joints, (C) 2012 El-Batahgy, licensee InTech.

[8] Nikhil Kumar, Manidipto Mukherjee, Asish Bandyopadhyay, Study on laser welding of austenitic stainless steel by varying incident angle of pulsed laser beam. Optics and Laser Technology 94 (2017) 296-309.

[9] Nabendu Ghosh, Pradip Kumar Pal, Goutam Nandi, Parametric Optimization of MIG Welding on 316L Austenitic Stainless Steel by Grey-Based Taguchi Method, Procedia Technology 25 ( 2016 ) 1038 - 1048.

[10] M.R. Pakmanesh, M. Shamanian, Optimization of pulsed laser welding process parameters in order to attain minimum underfill and undercut defects in thin 316L stainless steel foils, Optics and Laser Technology 99 (2018) 30-38.

[11] T. Ramkumar, M. Selvakumar, P. Narayanasamy, A. Ayisha Begam, P. Mathavan, A. Arun Raj,Studies on the structural property, mechanical relationships and corrosion behaviour of Inconel 718 and SS 316L dissimilar joints by TIG welding without using activated flux, Journal of Manufacturing Processes 30 (2017) 290-298. 
[12] Banakara Nagaraj, Dr. V. Venkataramana,Empirical Modeling \& Experimental Investigations of NdYAG Laser beam welding process parameters of Inconel- 825 using RSM, International Journal of Pure and Applied Mathematics, Volume 119 No. 18 2018, 2705-2709.

[13] M. Arivarasu, P. Roshith, R. Padmanaban, S. Thirumalini, K. V. Phani Prabhakar \& G. Padmanabham, Investigations on metallurgical and mechanical properties of CO2 laser beam welded Alloy 825, The Canadian Journal of Metallurgy and Materials Science,(2017).

[14] Ceyhun Köse, Ramazan Kaçar, Ashı Pınar Zorba, Melahat Bağırova, Adil M. Allahverdiyev, The effect of $\mathrm{CO} 2$ laser beamwelded AISI 316L austenitic stainless steel on the viability of fibroblast cells, in vitro. Materials Science and Engineering C 60 (2016) 211-218.

[15] Rakesh Bhadra, Pankaj Biswas and M. Ravi Sankar, Effect of process parameters on thermal history of laser welding of AISI-304 stainless steel, Design and Research Conference (AIMTDR 2014).

[16] J. Kell, j. R. Tyrer, r. L. Higginson \& R. C. Thomson, Microstructural characterization of autogenous laser welds on 316L stainless steel using EBSD and EDS, Journal of Microscopy, Vol. 217, Pt 2 February 2005, pp. 167-173.

[17] Vicente Afonso Ventrellaa, José Roberto Berrettab, Wagnerde Rossib, Pulsed Nd:YAG laser seam welding of AISI316L stainless steel thin foils, Journal of Materials Processing Technology xxx (2010).

[18] Ahmed Selim Ebrahim Elmesalamy, Narrow Gap Laser Welding of 316L Stainless Steel for Potential Application in the Manufacture of Thick Section Nuclear Components,(2013).

[19] Longchao Cao, Yang Yang, Ping Jiang, Qi Zhou, Gaoyang Mi, Zhongmei Gao, Youmin Rong, Chunming Wang, Optimization of processing parameters of AISI 316L laser welding influenced by external magnetic field combining RBFNN and GA, Results in Physics 7 (2017) 1329-1338.

[20] Youmin Rong \& Yu Huang \& Guojun Zhang \& Gaoyang Mi \& Wenjun Shao, Laser beam welding of 316L T-joint: microstructure, microhardness, distortion, and residual stress, springer(2013).

[21] N. Sridhar and G.A. Cragnolino,Applicability of Repassivation Potential for Long-Term Prediction of Localized Corrosion of Alloy 825 and Type 316L Stainless Steel, CORROSION-Vol. 49(1993).

[22] Nikhil Kumar, Manidipto Mukherjee, Asish Bandyopadhyay ,Comparative study of pulsed Nd:YAG laser welding of AISI304 andAISI 316stainlesssteels, Optics \&LaserTechnology88(2017)24-39.

[23] Ceyhun Köse, Ramazan Kaçar , Aslı Pınar Zorba , Melahat Bağırova , Adil M. Allahverdiyev, The effect of CO2 laser beamwelded AISI 316L austenitic stainless steel on the viability of fibroblast cells, in vitro, Materials Science and Engineering C 60 (2016) 211-218.

[24] H.Ramakrishnan, "Design, fabrication and analysis of fume extraction and filtration equipment', Pakistan Journal of Bio-technology, Vol.14 (1), 2017, pp 101-103.

[25] Yih-fong Tzeng, "Parametric analysis of the pulsed Nd:YAG laser seamwelding process", Journal of Materials Processing Technology 102

(2010). 